\title{
FORMATION OF POSITION IN PRIMARY SCHOOL CHILDREN IN PHYSICAL CULTURE LESSONS
}

\author{
Anastasia Melnik ${ }^{1}$, Olga Shevchenko ${ }^{2}$ \\ ${ }^{1}$ Ph.D. (Pedagogy), Associate Professor, Associate Professor of the Department of Theory and methods of \\ physical education, Volodymyr Vynnychenko Central Ukrainian State Pedagogical University, \\ Kropyvnytskyi, Ukraine, e-mail: nastenkamelnik89@gmail.com, ORCID: https://orcid.org/0000-0001-7785- \\ 4168 \\ ${ }^{2}$ Ph.D. (Pedagogy), Associate Professor, Head of the Department of Theory and methods of physical \\ education, Volodymyr Vynnychenko Central Ukrainian State Pedagogical University, Kropyvnytskyi, \\ Ukraine, e-mail: gimnast.olga@gmail.com,ORCID: https://orcid.org/0000-0002-9493-348X
}

\begin{abstract}
The article considers the problem of posture formation in children of primary school age in physical education lessons. Diseases of the musculoskeletal system, including scoliosis and flat feet - is a problem of today with a thousand-year history. Therefore, doctors claim that recently the number of people with scoliosis and flat feet is growing significantly. The analysis of the literature showed that for the correction and prevention of posture requires a clear and purposeful use of physical education in the daily routine of students, as well as the creation and observance of certain hygienic conditions. We have proposed a set of physical exercises and therapeutic physical culture to solve this problem. The purpose of the study is contained in the methodological and theoretical substantiation of the foundations of the formation of the culture of movements of primary school students with posture defects through the interaction of gymnastic exercises and therapeutic physical culture. The set of gymnastic exercises should be developed individually taking into account the main pathological components of spinal deformity, the nature of scoliotic deformity. In the complexes of therapeutic gymnastics, much attention is paid to breathing exercises, which not only increase the functionality of the respiratory and cardiovascular systems, but also contribute to the active correction of the spine and chest. Thus, based on the results obtained in the experiment, we are able to claim that our proposed method of gymnastic special exercises has had a positive effect on posture development, improved movement culture and general physical development. Thus, research work requires further search for effective tools and methods of physical education for schoolchildren.
\end{abstract}

Keywords: posture, physical culture, physical exercises, medical physical culture, children of primary school age.

JEL Classification: I0; I20

Formulas: 0; fig.: 0; tabl.: 1; bibl.: 11

Introduction. Nowadays, the world community considers individual and public health to be a universally recognized value. The health of the nation is seen as an indicator of the civilization of the state, reflecting the socio-economic situation of society. According to UN Resolution №38 / 54 of 1997, public health is considered the main criterion of expediency and efficiency of all spheres of economic activity without exception. Moreover, experts believe that about $75 \%$ of diseases in adults is the result of living conditions in childhood and adolescence. Diseases of the musculoskeletal system, including scoliosis and flat feet - is a problem of today with a thousand-year history. Sitting at a desk, carrying bags with textbooks and modern loads in the crazy pace of life become a real challenge for the human spine. Therefore, doctors claim that recently the number of people with scoliosis and flat feet is growing significantly $[9,10]$. 
It is very important at school to pay attention to how the child sits at the desk and behaves in everyday life. The problem of treatment and prevention of scoliosis and flat feet today is relevant and very important. Today, according to statistics, 7$8 \%$ of the population suffers from spinal diseases. Treatment of scoliotic spinal deformity has always been and is one of the most difficult issues in orthopedics. The Institute of Orthopedics and Traumatology of the Academy of Medical Sciences of Ukraine (Kyiv) is one of the leading centers in the field of traumatology and orthopedics, which studies diseases related to the musculoskeletal system of man. The Institute has developed a number of priority scientific problems that are of great importance for the development of domestic traumatology and orthopedics. It is here that the method of prevention and treatment of scoliosis was developed. The State Institution «M.I. Sytenko Institute of Spine and Joint Pathology of the Academy of Medical Sciences of Ukraine» (Kharkiv) is also studying the problems related to spinal diseases [3, 4].

According to available statistics, the prevalence of posture disorders among schoolchildren is $40-50 \%$. Issues of posture disorders are described in detail in the works of domestic and foreign authors. However, this problem remains relevant today, arousing the interest of specialists in the field of physical education, sports and human health.

Posture is unstable during the period of increased growth of the child's body, which falls on the primary school age. This is due to the simultaneous development of the bone, joint and ligament apparatus and muscular system of the child. The creation of a new type of secondary school leads to overloading of the child's body due to the increase in the duration of classes and the volume of educational material. The total amount of knowledge that students receive in a modern Ukrainian school far exceeds their ability to master it, which leads to the deterioration of children's health. In particular, this is the cause of deviations from normal posture. A year after starting school, the number of children with postural pathology increases significantly [2, p. 76].

Posture defects create conditions for the manifestation of diseases of the spine and other organs of the musculoskeletal system, which leads to disorders of the internal organs. In children with posture disorders, the vital capacity of the lungs is reduced, the excursion of the chest and diaphragm is reduced, which creates unfavorable conditions for the activity of the cardiovascular and respiratory systems. Abdominal muscle weakness contributes to the disruption of the normal functioning of the abdominal organs. Decreased spinal function in children with a flat back causes constant brain microinjury during walking, running and other movements, which negatively affects higher nervous activity, is accompanied by a rapid onset of fatigue and often headaches [6, p. 251].

In the system of physical education of schoolchildren with postural disorders, mainly one means of correction is used - physical exercises. All this led to the choice of research topic and gives grounds to consider this problem relevant to the modern educational and correctional process. 
Literature Review. The problem of physical education of the younger generation is one of the most important at the present stage of development of society. Leading specialists, scientists O.D Dubogai, A.M. Laputin, V.O. Kashuba and others note that the formation of correct posture in children is one of the main pedagogical problems of school physical education. Numerous studies have shown that the process of physical education in school should provide objective control over the formation of the correct posture of students [5].

The human musculoskeletal system performs many functions, at the same time, in the process of development it is under the influence of various factors and is subject to certain changes, including pathological ones. One of the causes of deviations in health, reduced physical development, the emergence of pathological processes is a violation of the posture of the human body [2].

The scientific literature on the problems of children's posture sufficiently covers the issue of diagnosing the degree and nature of postural disorders.

The anatomical and physiological features of the formation of the musculoskeletal system of school-age children are revealed. Knowledge of which is a necessary condition for the successful development and implementation of preventive and health measures with the use of physical exercises aimed at improving posture and preventing its violation in children [1, p. 18-22].

Researchers R.A. Bannikova, M.E. Verich, I.V. Penkova, O.G. Sukharev and others determine that posture is an integrative indicator of children's health, even minor functional disorders can cause permanent deformation of the musculoskeletal system, which leads to serious consequences for children's health. An important condition for solving this problem, according to B.M. Mickan and E.S. Vilchkovskiy is an increase in skeletal muscle tone, which affects the formation of proper posture, is a consequence not only of improving the regulatory function of the central nervous system, but also the positive effects of exercise on the body of students.

Analysis of scientific and methodological literature [2, 4] shows that the violation of motor function of the spine and its morphofunctional changes occur usually due to changes in posture, as a result of which the spine can not withstand excessive mechanical loads and deforms and warps in the most vulnerable places.

The formation of the correct posture, prevention of defects - one of the most important tasks of physical education. The correct posture, as noted in the works of V.K. Vetlichenko, V.N.Seluyanova, V.O. Kashuba is important not only from an aesthetic point of view, but also from a physiological point of view: creating the best conditions for the activity of the whole organism, it provides a rational position and normal functioning of internal organs, promotes the lowest energy expenditure, increases efficiency [6].

The analysis of the literature showed that for the correction and prevention of posture defects it is necessary to clearly and purposefully use the means of physical education in the daily routine of schoolchildren, as well as the creation and observance of certain hygienic conditions $[1,4,6]$.

At the international scientific-practical conference «Children's Health» (Kyiv, 2003) the expediency of comprehensive use of various means of correction of 
postural disorders was noted. For the first time in Ukraine, such an approach to assessing the posture and physical development of children and adolescents, which diagnoses a quantitative assessment of physical health, was proposed by V.A. Shapovalova. Based on this method, a computer information and diagnostic program «Schoolboy» was developed, which is used for mass diagnostics of posture, physical health and rehabilitation and correction of children by means of therapeutic physical culture.

The above gives grounds to state the relevance of the chosen research topic, which is due on the one hand to the severity of the problem of school health, and on the other - the need to find effective solutions, which is certainly theoretical and practical significance for improving physical education.

Aims. The purpose of the study is contained in the methodological and theoretical substantiation of the foundations of the formation of the culture of movements of primary school students with posture defects through the interaction of gymnastic exercises and therapeutic physical culture.

We set the research objectives:

- to analyze the literature and research theory;

- to determine the specific essence of the formation of the culture of primary school students with posture defects;

- to identify the level of formation of posture in primary school students;

- to develop a method of forming the correct posture in junior high school students and test it experimentally in physical education lessons in the interaction of gymnastic exercises and therapeutic physical culture.

Methods. The following research methods were used to solve the problems of the pedagogical experiment:

1. Analysis of scientific and methodological literature

2. Pedagogical observations

3. Diagnostic methods.

4. Pedagogical experiment

5. Methods of mathematical (variational) statistics

Analysis of scientific and methodological literature. The analysis of scientific and special literature was carried out in order to study the state of the problem of the influence of gymnastic exercises on the formation of the culture of movements and the relevance of this problem. The basis of the literary analysis were considered: problems and prospects of active use of various means of gymnastics to improve the culture of movement in schoolchildren. Analysis of the literature allowed to characterize the correct posture and the factors that cause various posture disorders. The anatomical and physiological features of the formation of the musculoskeletal system of school-age children are revealed. Knowledge of which is a necessary condition for the successful development and implementation of preventive and health measures with the use of physical exercises aimed at improving posture and preventing its violation in children.

Pedagogical observation. In our study, the observation was conducted in order to study the culture of movements of primary school children as an indicator of 
general culture; in order to identify the ability of students to maintain proper posture throughout the lesson. During the observation, attention was also paid to children's postures, their facial expressions and gestures, etc.

Diagnostic methods. We have developed tests to identify the impact of gymnastic exercises on the formation of the culture of movements of primary school children.

Test 1. «Posture» - walking on a bench, keeping the posture, pre-recorded near the wall.

The student stands with his back to the wall so that the back of his head, shoulders, buttocks and heels touch the wall, then moves away, and tries to maintain the correct posture, walks on the gymnastic bench. The ability to maintain the correct posture (without straining) in the process of walking on the bench is assessed. The test, which focuses on the formation of the correct posture as the basis of plasticity, also includes the use of additional load.

Test 2. «Plasticity» - a wave of the body.

Standing half a step from the gymnastic wall facing her, hands forward grip on top of the wall. The wave is performed by the torso from a circular squat. The degree of fusion of movement is revealed: alternate touching of knees, hips, a breast and smooth return to a semi-squat.

Test 3. «Coordination» - a general developmental exercise - currently.

Perform three general developmental exercises - currently. Clear performance of exercises and correct transition from one exercise to another (merger of performance of exercises), preservation of dynamic posture is estimated.

Pedagogical experiment. Pedagogical experiment - a fundamental method of research in physical education. According to the orientation, pedagogical experiments are divided into absolute and comparative. In our case, a comparative experiment. The comparative experiment is organized with a strict focus on establishing some new factor in the pedagogical process. In this case, we used as an experimental factor the influence of gymnastic and choreographic exercises on the general culture of movements of primary school students with posture defects.

Method of mathematical and statistical processing of results. This method was used to process the obtained results, which makes it possible to evaluate the obtained results not only from the qualitative point of view, but also from the quantitative point of view [7]. To process the average results were used:

- The arithmetic mean;

- The standard deviation;

- Medium error;

- Student's criterion.

To formalize the reliability of the differences between the average universal and definitive indicators find the koefficient $\mathrm{T}$.

Results. As a result of observation, we found that a significant number of children do not follow their posture and pay attention to the posture only when the teacher reminds them of it. The muscles of the back and abdomen are mostly relaxed, 
there is no smoothness when performing the exercises, but children happily try to look like their teacher when the teacher performs the exercise well and correctly.

Discussion. Posture is the ability of a person to hold his body in different positions. Posture can be right or wrong.

The correct posture is called the usual posture of a relaxed person who has the ability to keep the body and head straight without unnecessary active stress. A person with the correct posture has an easy gait, shoulders are slightly lowered and set back, chest forward, abdomen tightened, legs bent at the knees.

With the correct posture, the head and torso are on the same vertical line, the shoulders are deployed, slightly lowered and both are on the same level, the shoulders are pressed, the chest is slightly convex, physiological curves of the spine are normal (no more than $4 \mathrm{~cm}$ ), legs are straight at the knees and pelvis. joints. The correct posture is characterized by the same level of shoulders, nipples, shoulder blades, equal length of cervical-shoulder lines (interval from ear to shoulder joint), depth of waist triangles, straight vertical line of spinous processes of the spine, evenly expressed physiological squamous curves, however cells and lumbar region (when leaning forward). Normally, the depth of lordosis in the cervical and lumbar spine coincides with the thickness of the palm of the subject. Deviation of these indicators from the norm indicates a violation of posture or scoliosis [1].

A significant role in the comprehensive treatment of children and adolescents with postural disorders belongs to exercise therapy, which is used in the sanatorium mode, and in particular in diagnostic modes. Exercise therapy is indicated for all children with postural disorders, as it is the only leading method that effectively strengthens the muscle corset, balances muscle tone, front and back of the torso, thighs. The main means of exercise therapy used for posture disorders in children are exercise, and massage and position therapy - an additional [8].

These classes should be held systematically, at least three times a week, in groups of 10 - 15 people or individually. The exercise course lasts for students $1.5-2$ months, the break between courses is 1 - 2 months. Under the influence of exercise in the body there are a variety of positive structural and functional changes. In this case, the more intense (but optimal for these conditions) physical activity, the more active the processes during recovery and the more significant changes.

There are preparatory ( 1 - 2 weeks), main (4 - 5 weeks) and final (1 - 2 weeks) part of the course of exercise therapy. In the preparatory part of the course of exercise therapy are used familiar exercises with a small and medium number of repetitions of exercises. The visual perception of the correct posture and its imaginary representation is created, the level of the general physical fitness raises. In the main part of the course of exercise therapy increases the number of repetitions of each exercise. The main tasks of correction of existing posture disorders are solved. In the final part of the course of exercise the load decreases, the number of repetitions of each exercise - decreases. Throughout the course, unloading initial positions are applied lying on the back, abdomen, side, standing in the knee-elbow position.

In the complex of conservative treatment of scoliosis gymnastics occupies a prominent place. The set of gymnastic exercises should be developed individually 
taking into account the main pathological components of spinal deformity, the nature of scoliotic deformity. The use of gymnastic exercises for therapeutic purposes in posture defects should primarily provide morphological correction, the formation of skills of correct posture, normalization of cardiovascular and respiratory systems and gastrointestinal tract on the background of general developmental effects. In the complexes of therapeutic gymnastics, much attention is paid to breathing exercises, which not only increase the functionality of the respiratory and cardiovascular systems, but also contribute to the active correction of the spine and chest. During the performance of exercises it is necessary to constantly pay attention to education and consolidation of the skill of correct posture, to demand exact performance of exercises [11, p. 62-63].

We started the formation of the culture of movements in the experimental part with the use of simple exercises, which are often elements of a coherent chain during gymnastic exercises. According to the classification of simple exercises, we divided into: relaxation exercises, different types of moves, ground exercises.

To combine the movements and actions of primary school students, it was proposed to study gymnastic movements, namely on the toes, in a squat, soft step, sharp, rolling, spring, lunges and others. During the performance, the experimenter required the girls to keep a clear posture, head and arms. For example, when learning a soft step, children had to bring out a leg with an outstretched toe and a straight knee, slowly lowering it from the sock to the floor and only then move on to the next step. Hand movements and splashes in the palm were added for mastering. In addition, relaxation movements were to promote more flexible performance of tasks. Students studied them with increased interest because tightness was required everywhere. Relaxation was performed with both the hands and the whole body, but the focus was on the gradual movements in the joints.

In the experimental group, students performed special exercises: 1) to form the correct posture and keep it in motion (walking) - a series of exercises for balance (types of walking on a gymnastic bench, including with a load (sandbag)); 2) for the development of plasticity, which included a series of exercises, represented a variety of "waves" of the body to the side, forward, backward, wavy movements of the hands in different directions; 3) for the development of coordination - general developmental exercises that were performed currently.

Conclusion. In the process of physical education classes in the experimental group, we gradually added a variety of traditional and non-traditional types of gymnastics. New non-traditional types of gymnastics (rhythmic, plastic, yoga, stretching) teach conscious control over the performed movements, self-control, mastering the ability to feel your body, muscles, relax. Exercises are aimed at relieving excessive stress, educating lightness, harmony, beauty and culture of movement.

We proposed a set of exercises for the formation of posture, which consisted of exercises for the formation of flexibility and coordination of motor skills:

1) tilts of the torso forward, backward, to the sides with the maximum amplitude - 10-15 times; 
2) circular movements of the torso to the right and left - 10-12 times;

3) "bridge" from a supine position 0-3-5 times;

4) walking on a gymnastic bench, 5-7 times;

5) walking on a sloping bench, 4-6 times;

6) walking on a gymnastic bench with movement through objects $10-15 \mathrm{~cm}$ high, 4-6 times.

The results obtained in the experimental group: posture improved by $41 \%$, plasticity by $43.7 \%$ and coordination by $44.5 \%$ This suggests that the means of physical culture have a positive effect on the development of both posture and plasticity and coordination of movements. In the experimental group, we purposefully used in each lesson a variety of gymnastic exercises for posture, the development of plasticity and coordination. During the experiment, we obtained the following results, which are shown in table 1 .

Table 1. Test results in the experimental group at the beginning of the experiment and after it

\begin{tabular}{|l|c|c|c|c|}
\hline \multicolumn{1}{|c|}{ Name } & $\begin{array}{c}\text { Before the start } \\
\text { of the experiment }\end{array}$ & $\begin{array}{c}\text { After the end of } \\
\text { the experiment }\end{array}$ & Difference & \% \\
\hline Posture & 2,58 & 4,37 & 1,79 & 41 \\
\hline Plastics & 2,3 & 4,08 & 1,88 & 43,7 \\
\hline coordination & 2,45 & 4,41 & 1,96 & 44,5 \\
\hline
\end{tabular}

Thus, based on the results obtained in the experiment, we are able to claim that our proposed method of gymnastic special exercises has had a positive effect on posture development, improved movement culture and general physical development. Thus, research work requires further search for effective tools and methods of physical education for schoolchildren.

Author contributions. The authors contributed equally.

Disclosure statement. The authors do not have any conflict of interest.

References:

1. Andryanov, V.L. (1985), Zabolevaniya i povrezhdeniya pozvonochnika u detej i podrostkov. Lvov, 18-22 [in Russian].

2. Apanasenko, G.L. (1998), Medycynskaya valeologyya. Kyev, 280 s. [in Russian].

3. Bukov, Yu.A. (2004), Teoretycheskye osnovi valeologyy. Symferopol, 135 s. [ in Russian].

4. Vajnrub, E.M. (1988), Gygyena obuchenyya i vospytaniya detej s narusheniyamy osanky i bolnix skolyozom. Kyev, $120 \mathrm{~s}$. [ in Russian].

5. Dugobaj, A.D. (1989), Fyzkultura: mы i dety. Kyev, 144 s. [ in Russian].

6. Encyklopediya fizychnoyi reabilitaciyi. Kirovorad, 2008. - 920 s. [in Ukrainian].

7. Zacyorskyj, V.M. (1982), Osnovы teory i yzmerenyj. Moskva, s. 21-26 [ in Russian].

8. Nazarenko, L.D. (2004), Эstetyka fyzycheskyx uprazhnenyj. Moskva, 249 s. [ in Russian].

9. Programa rozvytku osvity Ukrayiny na 2005-2010 roky: Proekt // Vy`shha osvita Ukrayiny`, 2005. - s.76103 [in Ukrainian].

10. Semenyuk, O.A. (2007), Valeologichna osvita v navchalnyx zakladax Ukrayiny: stan, napryamky i perspektyvy rozvytku. Kirovograd, 296 s. [in Ukrainian].

11. Yazloveczkyj, V.S. (2011), Likuvalna fizychna kultura. Kirovograd, 252 s. [in Ukrainian].

Received: November 22, 2020

Approved: December 10, 2020 